\title{
Erratum to: Assays of the Amino Acid Tryptophan in Cherries by HPLC-Fluorescence
}

\author{
J. Cubero • F. Toribio • M. Garrido • M. T. Hernández • \\ J. Maynar • C. Barriga • A. B. Rodríguez
}

Published online: 27 August 2011

(C) Springer Science+Business Media, LLC 2011

Erratum to: Food Anal. Methods (2010) 3:36-39

DOI 10.1007/s12161-009-9084-1

The original version of this article unfortunately contained a mistake. On page 36, the abstract in the sixth line from the last: "g" should be " $\mu \mathrm{g}$ " (micrograms).

The online version of the original article can be found at http://dx.doi. org/10.1007/s12161-009-9084-1.

J. Cubero $(\triangle) \cdot$ M. Garrido $\cdot$ C. Barriga $\cdot$ A. B. Rodríguez

Department of Physiology, Faculty of Science,

University of Extremadura,

Av. de Elvas $\mathrm{s} / \mathrm{n}$,

CP: 06061 Badajoz, Spain

e-mail: jcubero@unex.es

F. Toribio $\cdot$ J. Maynar

Department of Analytical Chemistry, University of Extremadura,

Badajoz, Spain

M. T. Hernández

Agrifood Technological Institute, Junta de Extremadura,

Badajoz, Spain 